\title{
Domestic violence: a hidden barrier to contraceptive use among women in Nigeria
}

This article was published in the following Dove Press journal:

Open Access Journal of Contraception

\section{Ghose Bishwajit Sanni Yaya}

Faculty of Social Sciences, School of International Development and Global Studies, University of Ottawa, Ottawa, ON, Canada
Correspondence: Ghose Bishwajit Faculty of Social Sciences, School of International Development and Global Studies, University of Ottawa, 75 Laurier Avenue East, Ottawa, ON KIN 6N5, Canada

$\mathrm{Tel}+\mathrm{I} 6132624856$

Email brammaputram@gmail.com
Background: The nonuse of family planning methods remains a major public health concern in the low-and-middle-income countries, especially due to its impact on unwanted pregnancy, high rate of abortion, and transmission of sexually transmitted diseases. Various demographic and socioeconomic factors have been reported to be associated with the nonuse of family planning methods. In the present study, we aimed at assessing the influence of domestic violence (DV) on contraceptive use among ever married women in Nigeria.

Methods: Data on 22,275 women aged between 15 and 49 years were collected from the most recent Nigeria Demographic and Health Survey conducted in 2013. The outcome variable was contraceptive utilization status, and the main exposure variable was DV, which was assessed by the self-reported experience of physical and psychological abuse. Complex survey method was employed to account for the multistage design of the survey. Data analyses were performed by using bivariate and multivariable techniques.

Results: The mean age of the participants was $31.33 \pm 8.26$. More than four fifths ( $84 \%)$ of the participants reported that they were not using any contraceptive methods at all. Lifetime prevalence of psychological and physical abuse was, respectively, $19.0 \%(95 \% \mathrm{CI}=18.0-20.1)$ and $14.1 \%(95 \% \mathrm{CI}=13.3-14.9)$. Women who reported physical abuse were $28 \%$ (adjusted odds ratio $[\mathrm{AOR}]=1.275 ; 95 \% \mathrm{CI}=1.030-1.578)$, and those reported both physical and psychological abuse had $52 \%(\mathrm{AOR}=1.520 ; 95 \% \mathrm{CI}=1.132-2.042)$ higher odds of not using any contraception. Conclusion: The rate of contraception nonuse was considerably high and was found to be significantly associated with DV. Thus, the high prevalence of DV may compromise the effectiveness of the family planning programs in the long run. Evidence-based intervention strategies should be developed to protect the health and reproductive rights of the vulnerable women and to reduce DV by giving the issue a wider recognition in public policy making.

Keywords: contraceptive non-use, demographic and health survey, spousal violence, physical abuse, psychological abuse

\section{Introduction}

Family planning programs constitute a crucial public health component in terms of offering the services and commodities, including contraceptives, which enable communities to achieve their reproductive goals such as planned pregnancy, birth spacing, and maintaining desired number of children, to name a few. In the low-and-middleincome-countries, which account for almost all maternal and infant mortalities in the world, ${ }^{1}$ optimum utilization of family planning services is regarded as a pivotal strategy for attaining the sustainable development goals. ${ }^{2}$ Adoption of family planning/ contraceptive methods has proven to be highly beneficial for tackling the burden of 
unintended and unwanted pregnancies and unsafe abortions and for preventing the transmission of HIV/AIDS and other sexually transmitted diseases (STDs). ${ }^{3-6}$ Apart from decreasing the risk of exposure to high-risk births, unwanted pregnancies, and STDs, contraception is also regarded as a key to broader demographic, socioeconomic, and environmental goals, especially in countries facing sustainability challenges owing to high fertility rates. ${ }^{7}$

The demography of Nigeria, currently the most populous country in Africa, is characterized by high total fertility and maternal and child mortality rates. Since the introduction of the first population policy in 1988 with an explicit aim to curb fertility rate (from six children/family to an average of 4 children/family), ${ }^{8}$ there has been an increased emphasis on family planning programs throughout the country. However, according to recent statistics, the total fertility rate is still very high (5.5\% as of 2013) with an alarmingly high prevalence of unsafe abortion and maternal mortality in the country. ${ }^{9}$ Evidence suggests that over a quarter $(25 \%-35 \%)$ of the global maternal deaths could have been averted through universal access and adequate use of contraceptives. ${ }^{10}$ Despite these persistent challenges and well-documented benefits of contraceptive methods, the prevalence of nonuse remains considerably low in Nigeria, which is to a certain degree reflected through the high unwanted pregnancy and maternal and child mortality rates. ${ }^{11,12}$

There is a growing volume of studies on family planning demonstrating the influence of various individual, familial, geographic, sociocultural, and health care system-induced factors on the nonutilization and suboptimal utilization of contraceptive methods. Appreciable progress has been achieved to address the physical barriers to the uptake of contraceptive services. However, in many instances, more complex issues contextual to the native sociocultural structure, which are usually less responsive to the intervention strategies such as gender discrimination ${ }^{13}$ and domestic violence $^{14}$ (DV; also known as intimate partner violence [IPV] or abuse) lie behind the direct physical factors. While both men and women can be the subject of DV, in most cases its woman who are perpetrated, and the scope of the present study was also limited male-to-female type of violence only.

The definition of men-to-women violence can differ substantially depending on the contexts; however, according to the most widely accepted definition by World Health Organization, it refers to "the range of sexually, psychologically and physically coercive acts used against adult and adolescent women by a current or former male partner."15 Violence against women is a global issue that compromises their human rights, health, well-being, and the quality of life. No doubt the topic has emerged as a major theme in international conferences and attracted many policy and programmatic interventions. In spite of these efforts, DV is still rampant and continues to affect millions of lives worldwide to which Nigeria is no exception. According to recent estimates, DV is a widespread phenomenon in the country with its prevalence ranging from $17 \%$ to $78.8 \% .{ }^{16}$ Current medical literature provides ample evidence on the impacts of DV on women's reproductive health outcomes. ${ }^{17-19}$ However, that on the use of family planning/contraceptive use is rather scarce in Nigeria. Therefore, the present study was conducted with the objectives of providing updates on the situation of contraceptive use and DV and their correlation among ever married women in Nigeria. Country representative primary data on social issues are hard to achieve for countries with poor research infrastructure; therefore, we sourced the already-published data from Measure DHS, which is available for free to researchers. Although the data are secondary and cross-sectional in nature, it is expected that the findings of the present study will facilitate informed policy action aimed at addressing DV-related barriers to contraceptive use among Nigerian women.

\section{Conceptual framework}

DV is a complex social construct that can result as interplay between individual- and community-level factors with sociocultural norms and values and political priorities of the population. Regardless of the exact cause or origin, DV can pose serious obstacles to contraceptive use through several direct and indirect pathways. Direct pathways can include physical mutilation that results in reduced ability to access the available services. Depression, poor self-efficacy and self-esteem, and care-seeking behavior are among the indirect causes. DV can also impact the extent to which a woman can exercise her role or decide her health care priorities. A healthy spousal relation sets the basis for effective communication and understanding of each other's physical and psychological needs as well as joint decision making on their reproductive goals. Form this viewpoint, DV can also cause (or result from) power imbalance with a subsequent reduction in autonomy to effectively communicate her preferences. ${ }^{20}$ To calculate the independent association between DV and contraceptive use, we adjusted the analysis for variables that are conceptually relevant to the variables of interest. For instance, the accessibility and utilization of contraceptive methods can be influenced by various sociodemographic factors such as age, area of residence, and religious affiliation. Contraceptive 
use as an indicator of health literacy and behavior can vary substantially among individuals depending on the degree of educational attainment as well as financial capacity. From the perspective of gender equity, the sex of household head can play crucial roles on women's experience of DV and so can have decision making autonomy on the access to and utilization of reproductive health care services.

\section{Methods}

\section{Survey and sampling design}

Nigeria Demographic and Health Survey (NDHS) 2013 was the fourth round of DHS survey in Nigeria, which was implemented by the National Population Commission with the financial and technical assistance by ICF International provisioned through the United States Agency for International Development-funded MEASURE DHS program. DHS surveys are national representatives that collect information on a wide range of public health-related topics such as anthropometric, demographic, and socioeconomic factors; family planning; and DV. The survey covered men and women aged between 15 and 49 years and under- 5 children residing in noninstitutional settings. For sampling, a three-staged stratified cluster design was employed, which was based on a list of enumeration areas (EAs) from the 2006 Population Census of the Federal Republic of Nigeria. EAs are systematically selected units from the localities, which constitute the local government areas (LGAs). LGAs are subdivisions of each of the 36 administrative states (including the Federal Capital Territory called Abuja) and classified under six developmental zones in the country. EAs were used to form the survey clusters called primary sampling units. NDHS 2013 consisted of 904 clusters (372 in urban areas and 532 in rural areas) encompassing a total of 40,320 households from which 38,948 women were successfully interviewed with a response rate of $98 \%$. Fieldwork lasted from February 15,2013 , to the end of May of the same year and was carried out by 36 interviewing teams in each state plus one in the Federal Capital Territory of Abuja. A more detailed version of the survey was published elsewhere. ${ }^{21}$

\section{Variables}

The outcome variable was self-reported contraceptive utilization status. Respondents were asked whether they are currently using contraception. The options for answer were "yes" or "No." Those who commented "don't know" were also categorized as "no."

The explanatory variable of focus was DV, which was assessed by the responses to a set of questions on physical and psychological abuse. For psychological abuse, the following four aspects were taken into consideration: 1) ever been humiliated by husband/partner; 2) ever been threatened with harm by husband/partner; 3) ever been insulted or made to feel bad by husband/partner; and 4) experienced any emotional violence. The following three were used to proxy for physical abuse: 1) ever been pushed, shook, or had something thrown by husband/partner; 2) ever been slapped by husband/partner; and 3) ever been punched with fist or hit by something harmful by husband/partner.

A set of confounding variables were included in the analysis as well based on their relevance in light of previous studies such as age, religious affiliation, the type of residency, educational attainment, wealth status of households, sex of household head, and having decision making autonomy on own health care. Table 1 describes these variables.

\section{Analytical procedure}

As deemed necessary for complex survey designs, the data set was first converted to a plan file by adjusting for the sampling strata, primary sampling unit, and sampling weight. As the initial analysis, the basic sociodemographic characteristics of the participants were presented in terms of frequencies and percentages. Following descriptive analysis, $\chi^{2}$ tests were performed to check for the significant associations between the explanatory variables and use of contraception. Variables that were found to be significantly associated in the $\chi^{2}$ tests (at $p<0.25$ ) were selected for final regression analysis. ${ }^{22}$ In the final step, binary logistic regression model was used to calculate the odds ratios (OR) of the associations between contraceptive use and two types of DV. Contraceptive use status was modeled as a function of the two types of DV (physical and psychological) and was estimated by binary logistic regression, while adjusting for various demographic and socioeconomic parameters that were found (based on literature review) empirically and theoretically pertinent to the outcome and exposure variables. The results of regression analysis were presented as ORs along with their 95\% CIs as an indicator of significance as well as the precision of the OR values. For all associations, $p$-value of $<0.05$ was considered statistically significant. All the analyses were performed with SPSS Version 24 (IBM Corporation, Armonk, NY, USA).

\section{Ethical approval}

The protocol of DHS surveys was approved by the Ethics Committee of ORC Macro (Macro International Inc.). The study was based on the analysis of anonymized secondary data available in the public domain of DHS; therefore, no 
Table I Description of the sample population (NDHS 20I3)

\begin{tabular}{|c|c|c|c|}
\hline Variables & Description & n $(22,275)$ & $\%$ \\
\hline Age (mean/SD) & $(31.33 / 8.26)$ & & \\
\hline $15-19$ & Age of the respondent in the interview year & 1665 & 7.5 \\
\hline $20-24$ & & 3573 & 16.0 \\
\hline $25-29$ & & 4836 & 21.7 \\
\hline $30-34$ & & 3974 & 17.8 \\
\hline $35-39$ & & 3321 & 14.9 \\
\hline $40-44$ & & 2480 & II.I \\
\hline $45-49$ & & 2426 & 10.9 \\
\hline Residency type & Whether the respondent is a rural or urban resident & & \\
\hline Urban & & 8128 & 36.5 \\
\hline Rural & & 14,147 & 63.5 \\
\hline Religion & Type of religious affiliation & & \\
\hline Christian & & 11,732 & 52.7 \\
\hline Islam & & 10,195 & 45.8 \\
\hline Other & & 348 & 1.6 \\
\hline Educational attainment & Highest level of formal education attained by the respondent & & \\
\hline Nil & & 9417 & 42.3 \\
\hline Primary & & 4659 & 20.9 \\
\hline Secondary & & 6340 & 28.5 \\
\hline Higher & & 1859 & 8.3 \\
\hline Employed & Current employment status for payment & & \\
\hline No & & 6464 & 29.0 \\
\hline Yes & & $|5,8| \mid$ & 71.0 \\
\hline Wealth index & Index of relative wealth status of households based on the & & \\
\hline Poorest & possession of durable goods (eg, refrigerator and TV) and building & 4397 & 19.7 \\
\hline Poorer & material (eg, concrete and wooden), rather than personal income & 4679 & 21.0 \\
\hline Middle & & 4404 & 19.8 \\
\hline Richer & & 4448 & 20.0 \\
\hline Richest & & 4347 & 19.5 \\
\hline Sex of household head & Sex of the person responsible for managing the household and & & \\
\hline Male & making key decisions & $|9,23|$ & 86.3 \\
\hline Female & & 3044 & 13.7 \\
\hline Decision maker for own health care & Whether the respondent can make her health care decisions & & \\
\hline Respondent alone & independently, or jointly with husband, or has no say at all & 1392 & 6.6 \\
\hline Respondent and husband/partner & & 7274 & 34.7 \\
\hline Husband alone/other & & 12,217 & 58.7 \\
\hline
\end{tabular}

Abbreviation: NDHS, Nigeria Demographic and Health Survey.

additional approval was necessary. However, the approval for the reuse of the data was obtained by authors from DHS.

\section{Results}

\section{Descriptive statistics}

In total, 22,275 ever married women aged between 15 and 49 years (mean age of 31.33 years) were included in this study. Table 1 displays the basic demographic and socioeconomic characteristics of the participants. As Table 1 indicates, above one fifth $(21.7 \%)$ of the participants were in the age-group of 25-29 years, about two thirds were of rural residents, and about half were followers of Christian faith (52.7\%). The percentage of women who had no formal education was 42.3 , and percentages of primary- and secondary-level completion rate were, respectively, 20.9 and 28.5. The rate of current employment was $71 \%$. About two fifths of the women were living in the poorer-poorest households and less than a fifth in the richest. A vast majority of the households were male-headed ( $86.3 \%$ ), and only $6.6 \%$ of the women had the autonomy of deciding on their health care.

\section{Bivariate association between contraceptive utilization status and sociodemographic parameters}

The overall prevalence of contraceptive use among the participants was $16 \%(95 \% \mathrm{CI}=15.2-17.0) \cdot \chi^{2}$ tests of independence were conducted to assess the bivariate relationship between contraceptive use and the sociodemographic factors. Table 2 
indicates that the likelihood of using contraceptive was highest among women aged between 30 and 34 years, being urban residents, being followers of Christian faith, having secondary school qualification, not employed, living in the richer-richest and male-headed households, and making decision on health jointly with husbands/partners.

Table 3 presents the prevalence of the individual types of physical and psychological abuse. The combined prevalence of physical abuse was $14.1 \%(95 \% \mathrm{CI}=13.3-14.9)$, and that of psychological abuse was $19.0 \%(95 \% \mathrm{CI}=18.0-20.1)$.

\section{Multivariable regression analysis}

Table 4 summarizes the results of multivariable regression on the association between DV and contraceptive use. In total, five regression models were run, of which the first three were univariate (unadjusted), one partially adjusted, and one fully adjusted. Contraceptive utilization status was regressed first against psychological abuse, second against physical abuse, and then against both. All three types showed significant association with the nonuse of contraceptives, with the OR being highest for those who reported experiencing physical abuse only (OR $=2.086 ; 95 \% \mathrm{CI}=1.842-2.363$ ). Although psychological abuse showed significant association in the univariate model, the significance was lost after partially adjusting for the other types of abuse and in the full model also adjusting for all the covariates. Importantly, the odds of nonuse both in the partially $(\mathrm{OR}=1.971 ; 95 \% \mathrm{CI}$ $=1.521-2.555)$ and in the fully adjusted (OR $=1.520 ; 95 \%$ $\mathrm{CI}=1.132-2.042$ ) models were highest for those reporting both psychological and physical abuse.

Table 2 Basic characteristics of the sample population stratified by contraception use status (NDHS 20I3)

\begin{tabular}{|c|c|c|c|}
\hline Variables (mean, SD) & Nonuser (84\%) & User (16\%) & $p$-value \\
\hline Age & & & 0.003 \\
\hline $15-19$ & $9.5(8.8,10.2)$ & I.I $(0.8,1.6)$ & \\
\hline $20-24$ & $17.6(16.9,18.3)$ & $10.2(9.1,11.4)$ & \\
\hline $25-29$ & $21.9(21.1,22.6)$ & $21.9(20.3,23.7)$ & \\
\hline $30-34$ & $16.7(16.1,17.4)$ & $23.1(21.5,24.9)$ & \\
\hline $35-39$ & $13.5(12.9,14.1)$ & $20.3(18.6,22.0)$ & \\
\hline $40-44$ & $10.0(9.6,10.5)$ & $15.3(14.0,16.8)$ & \\
\hline $45-49$ & $10.8(10.2,11.4)$ & $8.0(6.9,9.2)$ & \\
\hline Residency type & & & $<0.001$ \\
\hline Urban & $33.5(31.7,35.3)$ & $65.0(61.5,68.4)$ & \\
\hline Rural & $66.5(64.7,68.3)$ & $35.0(31.6,38.5)$ & \\
\hline Religious affiliation & & & $<0.001$ \\
\hline Christian & $35.7(33.6,37.9)$ & $75.6(72.7,78.4)$ & \\
\hline Islam & $62.6(60.3,64.8)$ & $23.4(20.7,26.3)$ & \\
\hline Other & $1.7(1.3,2.3)$ & $1.0(0.7,1.5)$ & \\
\hline Educational attainment & & & $<0.001$ \\
\hline $\mathrm{Nil}$ & $51.6(49.5,53.7)$ & $7.5(6.4,8.8)$ & \\
\hline Primary & $18.7(17.6,19.8)$ & $24.1(21.9,26.5)$ & \\
\hline Secondary & $23.7(22.3,25.1)$ & $50.9(48.2,53.7)$ & \\
\hline Higher & $6.1(5.4,6.8)$ & $17.4(15.2,19.9)$ & \\
\hline Employed & & & $<0.001$ \\
\hline No & $32.6(31.1,34.0)$ & $15.5(13.7,17.4)$ & \\
\hline Yes & $67.4(66.0,68.9)$ & $84.5(82.6,86.3)$ & \\
\hline Wealth index & & & $<0.001$ \\
\hline Poorest & $24.6(22.2,27.1)$ & $2.2(1.6,3.1)$ & \\
\hline Poorer & $23.3(21.8,25.0)$ & $6.4(5.1,8.0)$ & \\
\hline Middle & $18.9(17.5,20.4)$ & $16.0(13.9,18.3)$ & \\
\hline Richer & $17.4(16.1,18.7)$ & $28.9(26.3,31.6)$ & \\
\hline Richest & $15.8(14.5,17.2)$ & $46.5(43.0,50.0)$ & \\
\hline Sex of household head & & & $<0.001$ \\
\hline Male & $87.9(87.1,88.6)$ & $84.9(83.2,86.4)$ & \\
\hline Female & $12.1(11.4,12.9)$ & $15.1(13.6,16.8)$ & \\
\hline Decision maker for own health care & & & $<0.001$ \\
\hline Respondent alone & $5.1(4.6,5.5)$ & $13.4(1 \mid .8,15.3)$ & \\
\hline Respondent and husband/partner & $30.1(28.8,31.5)$ & $55.9(53.6,58.2)$ & \\
\hline Husband alone/other & $64.5(63.0,66.0)$ & $30.7(28.4,32.4)$ & \\
\hline
\end{tabular}

Abbreviation: NDHS, Nigeria Demographic and Health Survey. 
Table 3 Prevalence of ever experiencing psychological and physical violence by partners/husbands (NDHS 20I3)

\begin{tabular}{llll}
\hline Type of IPV & Categories & $\begin{array}{l}\text { Individual } \\
\text { prevalence (95\% Cl) }\end{array}$ & $\begin{array}{l}\text { Combined } \\
\text { prevalence (95\% Cl) }\end{array}$ \\
\hline Psychological & Ever been humiliated by husband/partner & $10.8(10.1-11.5)$ & $19.0(18.0-20.1)$ \\
& Ever been threatened with harm by husband/partner & $5.9(5.4-6.5)$ & $15.2(14.4-16.1)$ \\
& Ever been insulted or made to feel bad by husband/partner & $19.0(18.0-20.0)$ & $14.1(13.3-14.9)$ \\
Physical & Experienced any emotional violence & $6.9(6.3-7.4)$ & $12.9(12.2-13.7)$ \\
& Ever been pushed, shook, or had something thrown by husband/partner & $3.6(3.3-4.0)$ & \\
Both & Ever been slapped by husband/partner & $23.7(22.6-24.8)$ & \\
\hline
\end{tabular}

Abbreviations: IPV, intimate partner violence; NDHS, Nigeria Demographic and Health Survey.

Table 4 Regression analysis measuring the association between DV and contraceptive nonuse among Nigerian women (NDHS 20I3)

\begin{tabular}{|c|c|c|c|c|}
\hline Type of IPV & Unadjusted ORs $(95 \% \mathrm{Cl})$ & & $\begin{array}{l}\text { *Partially adjusted } \\
\text { ORs }(95 \% \mathrm{Cl})\end{array}$ & $\begin{array}{l}\text { **Fully adjusted ORs } \\
(95 \% \mathrm{Cl})\end{array}$ \\
\hline \multicolumn{5}{|l|}{ Psychological } \\
\hline \multicolumn{5}{|l|}{ No (ref) } \\
\hline Yes & $1.741(1.533-1.97)$ & & $0.839(0.67|-| .047)$ & $0.936(0.734-1.192)$ \\
\hline \multicolumn{5}{|l|}{ Physical } \\
\hline \multicolumn{5}{|l|}{ No (ref) } \\
\hline Yes & $2.086(1.842-2.363)$ & & $1.269(1.049-1.536)$ & $1.275(1.030-1.578)$ \\
\hline \multicolumn{5}{|l|}{ Both } \\
\hline \multicolumn{5}{|l|}{ No (ref) } \\
\hline Yes & & $1.985(1.77 \mid-2.226)$ & I.97I ( $(1.52 I-2.555)$ & $1.520(1.132-2.042)$ \\
\hline
\end{tabular}

Notes: Reference category is "no." ORs shown in bold are significant at $p<0.05$. *Adjusted for other types of IPVs; **adjusted for age, residency type, religious affiliation, educational attainment, wealth index, employment, sex of household head, decision maker for own healthcare.

Abbreviations: DV, domestic violence; IPV, intimate partner violence; NDHS, Nigeria Demographic and Health Survey.

\section{Discussion}

The present study was conducted with data derived from NDHS. The aims were to provide an update on the pattern of contraceptive use among currently married women as well as to measure the association between contraceptive use and DV. Several important findings emerged from this analysis that merit special attention. The overall prevalence of contraceptive use among the study participants was strikingly low with marked disparities across age and geographic and socioeconomic factors. Only $16 \%(95 \% \mathrm{CI}=15.2-17.0)$ of the women reported using any contraceptive method, which is far below the global level of $63.3 \%(60.4-66.0 \%)$ and African country average of $31 \%$ (as of 2010). ${ }^{23}$ The rate is higher than those in two previous NDHS surveys: $12.6 \%$ in 2003 and $14.6 \%$ in 2008. However, putting in comparison with other comparable economies such as Kenya $(42.1 \%)^{24}$ and Ethiopia $(29.2 \%)^{25}$ reveals that Nigeria has a long way to go to catch up with its regional counterparts. This slow progress in the prevalence of contraception is particularly thought-provoking, given the rising rate of female literacy and a fair level of knowledge regarding contraception in the population. ${ }^{26}$
Some plausible explanations behind this could be the occurrence of socioeconomic inequalities in accessing health care. Our results indicated that only $2.2 \%$ of the women in the households with poorest wealth status were using contraceptive method in contrast to $46.5 \%$ in the richest households. Similar findings were observed in countries across South Asia and sub-Saharan Africa including Bangladesh, ${ }^{1}$ India, ${ }^{27}$ Ghana, ${ }^{28}$ Kenya ${ }^{24}$ Ethiopia, ${ }^{25}$ and Zimbabwe ${ }^{29}$ that have reported a striking gap in the utilization of basic reproductive services among women in the richest and lowest wealth groups. Financial well-being at individual and familial levels has been shown to be a direct determinant of utilization of maternal health care and family planning services even when the services were available free of cost. ${ }^{30}$

The sexual and reproductive autonomy-related issues that usually arise from general power imbalance, marital discord, and spousal abuse come next to the direct socioeconomic determinants. Women reporting lifetime experience in IPV are significantly less likely to be able to use contraception and maintain their fertility goals. ${ }^{14}$ The relationship between IPV/DV and the use of family planning services is a hard one to clarify; however, the possible mechanisms appear to be 
the erosion of processes such as women's decision-making autonomy, self-esteem, and poor health care-seeking behavior. According to prior researches, women in 8 of 19 countries in sub-Saharan Africa were more likely to use contraception when they had greater decision-making autonomy. ${ }^{31}$ Lack of autonomy has also shown to be associated with poor uptake of contraception and maternal health care services in Bangladesh $^{32}$ and India. ${ }^{33}$ These findings are well in line with the ones from the present study. Surprisingly, we did not find any significant influence of psychological abuse on contraceptive use; however, that of physical abuse and the combination of both have demonstrated a strong association.

A good number of studies have been conducted so far at national and subnational levels that provided varying perspectives regarding the high fertility and the low use of maternal care and family planning services in Nigeria. The majority of the studies have argued surrounding the socioeconomic grounds, with only a few probing into the culture- and gender empowerment-related issues such as ethnicity, religion, the level of autonomy, and spousal abuse. ${ }^{34,35}$ Thus, the current evidence base may be such that addressing the socioeconomic factors emerges as the most compelling priorities to improve the coverage of family planning services. Even so, the findings of the present study imply the necessity for the prevention and intervention of DV, which may potentially contribute to the achievement of national family planning and demographic targets. DV is a multifaceted problem that cuts across a host of sociocultural factors, which means that any attempt to mitigate this will require a multisectoral policy approach stressing on issues including women empowerment, promoting women's rights, making gender-friendly public policies, and perhaps, the most important of all, raising public awareness. To facilitate this, further researches need to be carried out to better understand the contexts of spousal abuse and the pathways through which DV and women's ability to use family planning services interact.

This study has several strengths and limitations. First, it showed contraceptive use as a function of DV unlike the majority of the past studies that focused on socioeconomic and demographic factors. The quality of survey was high, and sample size was a representative of the population aged between 15 and 49 years. Data analysis followed a carefully selected set of procedures and was accounted for the complex nature of the sampling strategies. The cross-sectional nature of the data, which precludes making any causal inferences, and the use of self-reported indicators of the variables instead of objective measurement, which increases the chance of reporting bias, are among the limitations. Nonetheless, the findings provide important insights for policy makers and researchers and thus invite more in-depth surveys for future.

\section{Conclusion}

The findings of the present study indicate a remarkably low prevalence of contraceptive use among Nigerian women. The rate of DV was equally distressing and has shown a significant association with the adoption of contraception. In light of these findings, it is recommended that policy makers place special emphasis on developing strategies to protect women from any form of perpetration and to integrate gender issues to matters that concern women's reproductive health.

\section{Acknowledgments}

We thank Measure DHS for providing the data sets and the households who agreed to take part in the survey.

\section{Disclosure}

The authors report no conflicts of interest in this work.

\section{References}

1. Yaya S, Bishwajit G, Ekholuenetale M. Factors associated with the utilization of institutional delivery services in Bangladesh. PLoS One. 2017;12(2):e0171573.

2. Starbird E, Norton M, Marcus R. Investing in family planning: key to achieving the sustainable development goals. Glob Health Sci Pract. 2016;4(2):191-210.

3. Rowlands S. Contraception and abortion. J R Soc Med. 2007;100(10): 465-468.

4. Bishwajit G, Tang S, Yaya S, Feng Z. Unmet need for contraception and its association with unintended pregnancy in Bangladesh. $B M C$ Pregnancy Childbirth. 2017;17(1):186.

5. Galavotti C, Schnell DJ. Relationship between contraceptive method choice and beliefs about HIV and pregnancy prevention. Sex Transm Dis. 1994;21(1):5-7.

6. Haddad LB, Philpott-Jones S, Schonfeld T. Contraception and prevention of HIV transmission: a potential conflict of public health principles. J Fam Plann Reprod Health Care. 2015;41(1):20-23.

7. Levine R, Langer A, Birdsall N, Matheny G, Wright M, Bayer A. Contraception. In: Jamison DT, Breman JG, Measham AR, et al, editors. Disease Control Priorities in Developing Countries. 2nd ed. Washington, DC: World Bank; 2006. Available from: http://www.ncbi.nlm.nih. gov/books/NBK11771/. Accessed October 18, 2017.

8. Mazzocco K. Nigeria's new population policy. Int Health News. 1988;9(3):1, 12 .

9. Akinyemi A, Adedini S, Hounton S, et al. Contraceptive use and distribution of high-risk births in Nigeria: a sub-national analysis. Glob Health Action. 2015;8:29745.

10. Jain R, Muralidhar S. Contraceptive methods: needs, options and utilization. J Obstet Gynaecol India. 2011;61(6):626-634.

11. Chola L, McGee S, Tugendhaft A, Buchmann E, Hofman K. Scaling up family planning to reduce maternal and child mortality: the potential costs and benefits of modern contraceptive use in South Africa. PLoS One. 2015;10(6):e0130077. doi:10.1371/journal.pone.0130077.

12. Asamoah BO, Agardh A, Östergren P-O. Inequality in fertility rate and modern contraceptive use among Ghanaian women from 1988-2008. Int J Equity Health. 2013;12:37. 
13. Kossler K, Kuroki LM, Allsworth JE, Secura GM, Roehl KA, Peipert JF. Perceived racial, socioeconomic and gender discrimination and its impact on contraceptive choice. Contraception. 2011;84(3): 273-279.

14. Stephenson R, Koenig MA, Acharya R, Roy TK. Domestic violence, contraceptive use, and unwanted pregnancy in rural India. Stud Fam Plann. 2008;39(3):177-186.

15. Onoh R, Umeora O, Ezeonu P, Onyebuchi A, Lawani O, Agwu U. Prevalence, pattern and consequences of intimate partner violence during pregnancy at Abakaliki Southeast Nigeria. Ann Med Health Sci Res. 2013;3(4):484-491.

16. Ajah LO, Iyoke CA, Nkwo PO, Nwakoby B, Ezeonu P. Comparison of domestic violence against women in urban versus rural areas of southeast Nigeria. Int J Womens Health. 2014;6:865-872.

17. McFarlane J, Parker B, Soeken K. Abuse during pregnancy: associations with maternal health and infant birth weight. Nurs Res. 1996;45(1):37-42.

18. Murphy CC, Schei B, Myhr TL, Du Mont J. Abuse: a risk factor for low birth weight? A systematic review and meta-analysis. CMAJ. 2001;164(11):1567-1572.

19. Pallitto CC, O'Campo P. The relationship between intimate partner violence and unintended pregnancy: analysis of a national sample from Colombia. Int Fam Plan Perspect. 2004;30(4):165-173.

20. Sapkota D, Bhattarai S, Baral D, Pokharel PK. Domestic violence and its associated factors among married women of a village development committee of rural Nepal. BMC Res Notes. 2016;9:178.

21. Yaya S, Ekholuenetale M, Tudeme G, Vaibhav S, Bishwajit G, Kadio B. Prevalence and determinants of childhood mortality in Nigeria. $B M C$ Public Health. 2017;17(1):485.

22. Ghose B. Frequency of TV viewing and prevalence of overweight and obesity among adult women in Bangladesh: a cross-sectional study. BMJ Open. 2017;7(1):e014399.

23. Alkema L, Kantorova V, Menozzi C, Biddlecom A. National, regional, and global rates and trends in contraceptive prevalence and unmet need for family planning between 1990 and 2015: a systematic and comprehensive analysis. Lancet. 2013;381(9878):1642-1652.
24. Ettarh RR, Kyobutungi C. Physical access to health facilities and contraceptive use in Kenya: evidence from the 2008-2009 Kenya Demographic and Health Survey. Afr J Reprod Health. 2012;16(3): 48-56.

25. Tiruneh FN, Chuang KY, Ntenda PA, Chuang YC. Factors associated with contraceptive use and intention to use contraceptives among married women in Ethiopia. Women Health. 2016;56(1):1-22.

26. Egede JO, Onoh RC, Umeora OU, Iyoke CA, Dimejesi IB, Lawani LO. Contraceptive prevalence and preference in a cohort of south-east Nigerian women. Patient Prefer Adherence. 2015;9:707-714.

27. Rao BS, Mathada VC. Awareness and determinants of contraceptive use among nursing mothers in Bellary, Karnataka. J Clin Diagn Res. 2016;10(1):QC15-QC19.

28. Nyarko SH. Prevalence and correlates of contraceptive use among female adolescents in Ghana. BMC Womens Health. 2015;15:60.

29. Yaya S, Bishwajit G, Ekholuenetale M, Shah V. Inadequate utilization of prenatal care services, socioeconomic status, and educational attainment are associated with low birth weight in Zimbabwe. Front Public Health. 2017;5:35.

30. Acharya J, Kaehler N, Marahatta SB, Mishra SR, Subedi S, Adhikari B. Hidden costs of hospital based delivery from two tertiary hospitals in Western Nepal. PLoS One. 2016;11(6):e0157746.

31. Viswan SP, Ravindran TKS, Kandala NB, Petzold MG, Fonn S. Sexual autonomy and contraceptive use among women in Nigeria: findings from the Demographic and Health Survey data. Int J Womens Health. 2017;9:581-590.

32. Ghose B, Feng D, Tang S, et al. Women's decision-making autonomy and utilisation of maternal healthcare services: results from the Bangladesh Demographic and Health Survey. BMJ Open. 2017;7(9):e017142.

33. Patrikar SR, Basannar DR, Seema Sharma M. Women empowerment and use of contraception. Med J Armed Forces India. 2014;70(3):253-256.

34. Obasohan PE. Religion, ethnicity and contraceptive use among reproductive age women in Nigeria. Int J MCH AIDS. 2015;3(1):63-73.

35. Antai D, Adaji S. Community-level influences on women's experience of intimate partner violence and terminated pregnancy in Nigeria: a multilevel analysis. BMC Pregnancy Childbirth. 2012;12:128.
Open Access Journal of Contraception

\section{Publish your work in this journal}

Open Access Journal of Contraception is an international, peerreviewed, open access, online journal, publishing original research, reports, reviews and commentaries on all areas of contraception. In addition to clinical research, demographics and health-related aspects, the journal welcomes new findings in animal and preclinical studies

\section{Dovepress}

relating to understanding the biological mechanisms and practical development of new contraceptive agents. The manuscript management system is completely online and includes a very quick and fair peer-review system. Visit http://www.dovepress.com/testimonials.php to read real quotes from published authors. 